\title{
A contribution from psychoanalysis and neuroscience to a non- reductionist approach in economics
}

\author{
Saura Fornero ${ }^{1, *}$ \\ ${ }^{1}$ Psychologist, Psychotherapist, Group Analysis Professor School of Specialisation in Psychoanalytic Psychotherapy COIRAG, Turin, \\ Italy, full member and past president APRAGI (Turin, Italy), full member COIRAG (Italy)
}

\begin{abstract}
What connections can be identified between economics, psychoanalysis and neuroscience and why make them? These are different disciplines and it is unusual to approach them together. The scientific paradigm of complexity includes and broadens the positivist paradigm and invites us to learn to think in terms of relationships and processes, and therefore in interdisciplinary terms. Specifically, it has been noted that the study of economics tends to be independent of a precise knowledge of human operations, of what actually determines effective choices and behaviours. In this sense, both psychoanalysis - understood as a discipline that leads the human sciences to the need to equip themselves in order to also consider the socalled unconscious aspects - and neurosciences - for the study of the neurophysiological correlates of the mind - can help build knowledge based on a complex systemic view of economic processes and their peculiarities. From this perspective, the group analysis - as also applying the unconscious conceptualisation to the study of the groups and to the groups clinic -can constitute a theoretical-experiential laboratory for the analysis and verification of hypotheses consistent with complex objectives, in the setting of survey, research and practice in the scientific, political and social fields.
\end{abstract}

\section{Introduction}

In order to contribute to the construction of an interdisciplinary culture, of which this same conference is a significant example, I will include three directions in this intervention: the psychoanalytic, the epistemological and the neuroscientific.

The authors I refer to here are: S. Freud [1], W. Bion [2,3] and S. Foulkes [4], M. Benasayag [5] for the psychoanalytic part; C.G. Hempel [6], L. Wittgenstein [7], P.K. Feyerabend [8], E. Morin [9], M. McLuhan [10], P. MacLean [11], F. Capra [12], P.L. Luisi [12] for the epistemological one; and G. Rizzolatti [13], V. Gallese [14], L. Solano [15], M. Pagani [16], K. Pribram [17], M. Gill [17], M. Solms [18], O. Sacks [19], O. Van der Hart [20], B. Van der Kolk [21], P. Levine [22], S. Greenfield [23] for the neuroscientific part and its nascent integration with psychoanalysis.

With Professor Burlando [24-27] and with Apragi's colleagues [28-31], we have often observed that the prevailing economic theory does not seem to sufficiently take into account the reality of human behaviour and how the current state of our behaviour, knowledge and technologies would probably not allow conditions of effective sustainable existence for the planet and for its billions of human beings inhabitants.

Why, then, is it still very difficult to conceive and implement an economy (etymologically a 'house law') capable of theorising and practicing knowledge, and tools for the benefit of the common house?

\section{Psychoanalysis, Neuroscience, Economics}

Psychology, psychoanalysis and group analysis deal with the complex dynamics underlying all human behaviour. Neurosciences study the neurophysiology of the living. In their vast field, the enormous development of computer applications is producing interesting knowledge on human behaviour as detected by instrumental means too.

The basis of psychoanalysis is the unconscious, everything that individuals and groups are little or not at all aware of, and which, for precisely this reason, can lead to thinking and acting in an entirely irrational way. In 1921, after the tragedy of the First World War, Freud published a fundamental essay called "Group Psychology and the Analysis of the Ego" [1], where he questioned the possible reasons for such a dramatic, irrational and unstoppable conflict.

For psychoanalysis and for the group analysis which should result from it and which applies the conceptualisation of the unconscious even to the study of the group clinic - the reasons for the explosion of destructiveness in humans lie in the internal, unconscious conflict that characterises the civilised human. Briefly, in the evolved industrial civilisation, scientific and technological progress rewards humans by providing them with medical care, consumer goods, and the idea of a foreseeable future as manageable with the rational instruments of science and technology, however,

Corresponding author: fornero@libero.it 
in order to build, preserve and develop this civilisation, human have to renounce their instinctuality and the desires it generates, either surrendering to the frustration and the process of removal that can follow or trying to follow the impervious path of the transformation of the instinctual energy inhibited in a constructive adaptation to reality.

The internal conflict between the instinctual and the rational is unconscious and, if it becomes too strong, can also generate an unconscious discomfort This unrecognised discomfort will show itself through symptoms at the psychic or physical levels or both. From this perspective, then, the unstoppable and irrational destructiveness of wars, the management of the great processes of colonisation and migration, the same actual globalisation and the irresponsible exploitation of natural resources, in short the violence connected with micro and macro human phenomena, becomes an expression of the 'discomfort' of a planetary civilisation that fails to self-govern. Such a failure is due to the illusion of the absolute power of a reductive idea of rationality, which is reductive because it does not take into account the power of the unconscious. This idea of rationality is that which we find in the predominant economic conception. From an interdisciplinary perspective, it should be noted that in psychology, rationality means the integration between the different specific levels of human functioning. It is a very complex concept, that I will summarise as the integration between reality, the perception of reality, emotion, feeling, thought and behaviour. In psychology, rationality is the awareness of the relationship between one's own thinking (understood as the whole complex of mental representations, motivations and values), actions and the consequences of the relationship between the two.

Freud himself, although aware of the power of the unconscious, complained as a neurophysiologist about the lack of neurophysiological associations with the fundamental concepts of the psychoanalytic system he was building.

Currently, neuroscience provides the neurophysiological correlations of the psychoanalytic system in a copious and detailed way.

Neuroscientific confirmation of the psychoanalytic approach is indirect and, thus, particularly reliable. The contribution made by neurosciences to the effective knowledge of human behaviour is interdisciplinary, as it is transversal to the knowledge of humans and the world. A summary of this first part of this paper, then, is that a contribution that psychoanalysis and neuroscience can make to the construction of an economy equipped to produce effective disciplinary knowledge is the need to take into account that our actual behaviours, our choices and our beliefs, have components of which we are physiologically unconscious.

Putting the knowledge of human behaviour at the foundation of the phylogenetic physiology of the unconscious is fundamental for reasoning in an interdisciplinary way, in an epistemological perspective of systemic complexity.

So far, I have tried to show the methodological basis needed for answering the initial question. I will continue onto the subject of the core contents in the current cultural debate and in this conference.

The economic West of the planet is experiencing the third great revolution: after the change from the nomadic hunter-gatherers into permanent farmers, from farmers into employment in industry and services, we are intertwining our daily life with the set of computer technology and the internet. By the end of the 1960s, the position of Marshall McLuhan who claimed that "The medium is the message" had already caused sensation. Arguing that the content of information is secondary to what is conveyed was a heavy blow to the supporters of the primacy of the mind, intelligence, a still muchidealised idea of rationality. In his classical "Understanding Media: The Extensions of Man" [10], McLuhan proposed what seemed an original point of view, but today this is substantially confirmed by neuroscience, according to which every technological (from the wheel to electricity) invention strongly modifies the relationship of a human being with the world, because every technology affects the environment and, above all, because every invention (from writing onwards, as Plato's Socrates also affirmed) is an externalisation of some human function: the wheel makes walking seamless, writing is an externalisation of the memory, and electricity is an externalisation of our nervous system.

The neurophysiologist Paul MacLean established a tripartition of the brain in the 1960s that is still in use today [11]. According to MacLean, there are three main encephalic structures: the brainstem, the limbic system, and the neocortex. These three structures are filo- and onto-. genetically ordered: they go from the simplest brainstem to the very complex neocortex. Briefly, in the brainstem, also called reptilian brain precisely because it is structurally similar to that of reptiles, the so-called simple functions (related to our perception of the environment), primitive and binary (acceptance/rejection, good/bad, etc.) take place. The limbic system, which humans have in common with mammals, performs more articulated, emotional functions, including the basis for caring for the children, which is typical of mammals. The neocortex, finally, hosts imposing and important electromagnetic activity, necessary for the performance of cognitive and affective operations of constant integration with the other two systems.

The neocortex is, incidentally, the most evolved part of our brain, and it is inserted into a constant biochemical and electrical communication and exchange system with the limbic system and the brainstem. The presence of the neocortex, however, is not equivalent to the integration of the three parts of the brain. The integration of the three systems is not a biological process, but rather a complex cultural process, to which success many environmental and social factors must contribute.

Taking McLuhan into account again [10] and from the perspective of the conditioning superiority of the medium compared to the message, we can observe how our age is characterised by a unique pervasiveness of the "virtual". However, today as yesterday, it is the 
relationship between humans and their living environment that 'specialises' the brain functioning. Virtual reality is characterised by speed, instantaneousness, and constant accessibility, qualities that seem to disregard the space-time constraints of nonvirtual reality. These characteristics "engrave" (as Benasayag says [5]) our brain, mainly stimulating the limbic and brainstem systems. The neocortex is not a system that autonomously produces intelligence, thought, knowledge, and creativity. If not properly trained, and stimulated, neocortical activity applies itself to what it finds. Moreover, currently it is increasingly evident that the virtual medium conveys various contents (the message), but this is secondary to the modality (the medium itself) of their transmission, which conditions the overall cerebral functioning.

For example: children who use devices with touch technology to a large extent tend not to develop motor skills, or spatio-temporal and relational orientation appropriate to their age.

\section{Conclusion}

In the West, we are used to thinking of intelligence - the human capacity to analyse humans themselves, nature, the environment, relationships, in a synthesis of producing knowledge and transmitting it - as a characteristic of our species, however, today both experience and neuroscience tell us that the main characteristic of our species is not the search for meaning, the exercise of intelligence and discernment, rather it is the tendency to avoid any form of suffering and frustration.

This characteristic is typical of living beings in general, not just humans. The novelty of our times is in the meeting between this, IT and mass media technology that promote infinite and very accessible applications aimed at providing pleasure and fun. The so-called narcissistic pathologies - those centred on the difficulty/impossibility to govern impulses, to tolerate frustration, to evaluate the consequences of one's actions for oneself and others - are currently increasing.

Just a few years ago, with Professor Burlando, we noticed the singular resemblance between the main features of the pathologies of the narcissistic area and citing his work - the fact that a series of choices produced "an economic-financial system marked by the constant search for income and/or profits on very short average decision horizons, at any cost and without attention to the overall consequences of the activities carried out (for these reasons, this economic-financial system has also been defined as 'drugged' with reference to the compulsive, addictive and indifference characteristics on the medium-long term also on one's own life".

If we are experiencing the third great human revolution (after the agricultural and industrial revolutions), the contemporary attempt to reflect on the ongoing processes cannot avoid being be affected by our being similar to the Wittgenstein fish - which was the last to notice the water around itself. What some of us may see as the blurring of the 'human' -as we are used to live and think about it - will appear to the current digital natives and especially to their descendants in a completely different way.

In the systemic and complex evaluation of the balance between resources and limits, then, in economics as in other fields of knowledge, the contribution of psychoanalysis and neuroscience will be to build knowledge, aware of the possible implications posed by the constitutive and unconscious human characteristic of the avoidance of pain. The goal continues to be the difficult transition from ideology to knowledge, which - as Morin and others argue - is the fatigue of knowledge, that is to say the foundations, of the meanings and the responsibility of our living in the common home we call humanity.

\section{References}

1. S. Freud, Opere, 12 volumes, Bollati Boringhieri, Torino (1977).

2. W.R. Bion, Experiences in groups and other papers, Tavistock, London (1961).

3. W.R. Bion, Learning from experience, Heinemann, London (1962).

4. S.H. Foulkes, Therapeutic group analysis, Allen and Unwin, London (1964).

5. M. Benasayag, El cerebro aumentado, el hombre disminuido, Paidós, Buenos Aires (2015).

6. C.G. Hempel, Aspects of scientific explanation and other essays in the philosophy of science, The Free Press, New York (1965).

7. L. Wittgenstein, Tractatus Logico-Philosophicus, Kegan Paul, Trench, Trubner and Co., London (1922).

8. P. K. Feyerabend, Against method. Outline of an anarchistic theory of knowledge, NLB, London (1975).

9. E. Morin, La connaissance de la connaissanc, Le Seuil, Paris (1986).

10. M. McLuhan, Understanding Media: the Extensions of Man, Routledge \& Kegan Paul, London (1964).

11. P.D. McLean, A Triune Concept of the Brain and Behaviour, University of Toronto Press, Toronto (1973).

12. F. Capra, P. L. Luisi, The systems view of life: a unifying vision, Cambridge University Press, New York (2014).

13. G. Rizzolatti, C. Sinigallia, So quel che fai: il cervello che agisce e $i$ neuroni specchio, Cortina, Milano (2006).

14. M. Ammaniti, V. Gallese, La nascita dell'intersoggettività: lo sviluppo del sé tra psicodinamica e neurobiologia, Cortina, Milano (2014).

15. L. Solano, Tra mente e corpo. Come si costruisce la salute, Cortina, Milano (2013). 
16. M. Pagani, "Curriculum vitae et studiorum" [Online]. Available: http://www2.istc.cnr.it/sites/default/files/curricula/c urriculum_vitae_marco_pagani_10.pdf [Access date: 2nd March 2019].

17. K.H. Pribram, M.M. Gill, Freud's Project Reassessed, Basic Books, New York (1976).

18. M. Solms, O. Turnbull, The Brain and the Inner World: An Introduction to the Neuroscience of Subjective Experience, Other Press, New York (2002).

19. O. Sacks, The River of Consciousness, Knopf, New York (2017).

20. O. Van der Hart, E.R.S. Nijenhuis, K. Steele, The Haunted Self: Structural Dissociation and the Treatment of Chronic Traumatization, W.W. Norton \& Co., New York/London (2006).

21. B. Van der Kolk, The Body Keeps the Score: Brain, Mind, and Body in the Healing of Trauma, Penguin, London (2015).

22. P.A. Levine, In an Unspoken Voice: How the Body Releases Trauma and Restores Goodness, North Atlantic Books, Berkeley (2010).

23. S. Greenfield, Mind change: how digital technologies are leaving their mark on our brains, Random House, New York (2015).

24. R. Burlando, A. Geuna, V. Valli, Politica economica e macroeconomia, Carocci, Roma (2010).

25. R. Burlando, Scienze umane ed economia: una riflessione epistemologica, Quaderni di Gruppoanalisi, 18, Ananke, Torino (2014).

26. R. Burlando, Le crisi: prospettive attuali, origini e possibili sviluppi, Quaderni di Gruppoanalisi, 18, Ananke, Torino (2014).

27. R. Burlando, A. Tartaglia (ed.), Physical Limits to Economic Growth: Perspectives of Economic, Social, and Complexity Science, Routledge, London (2018).

28. S. Fornero, Attraversare lo schermo. Psicoanalisi e cinema di fronte al futuro, in De Biase F., I pubblici della cultura. Audience development, audience engagement, Franco Angeli, Milano (2014).

29. S. Fornero, Potere e limiti: economia $e$ gruppoanalisi dialogano intorno alla crisi Introduzione, Quaderni di Gruppoanalisi, 18, Ananke, Torino (2014).

30. S. Fornero, Crisi economica, individui, gruppi $e$ relazioni: un punto di vista gruppoanalitico, Quaderni di Gruppoanalisi, 18, Ananke, Torino (2014).

31. S. Fornero, Clinica del trauma e ottica gruppoanalitica, Quaderni di Gruppoanalisi, 19, Ananke, Torino (2015). 